\title{
Architecture and the graphic novel
}

\section{Laurence North \\ Falmouth University}

\begin{abstract}
Richard McGuire's Here (2014) and Chris Ware's Lost Buildings (Glass et al. 2004) are discussed as examples of graphic novels that demonstrate a synergistic relationship with architecture. The synergistic relationship is examined through its use of decorative forms and the use of architectural reference as a narrative device and a signifier of space and time. The article goes on to explore the potential for architectural structures to function as graphic novels. The late medieval frescos attributed to the architect and painter Giotto, that decorate the chapels at Assisi and Padua, are used as examples of illustrations that rely on their architectural context. Giotto's work is explored as a model to inform the development of the graphic novel into an architectural form. Laura Jacobus' and Jenetta Rebold Benton's analysis of Giotto's works at Padua and Assisi provide us with an understanding of Giotto's work and the importance of decorative features in relation to the audience's perception of real and pictorial space, experienced time and narrative time. Jacobus' and Rebold Benton's analysis is then applied to two of London's Art on the Underground projects by Wallinger and Trabizian and also The Factory, Hong Kong. At these contemporary architectural sites, images have been installed to rehabilitate mundane structures and enrich the users experience. The installed imagery allows users to become immersed in narratives by eroding barriers between real and pictorial space, experienced time and narrative time. These contemporary examples describe the graphic novel's potential to be authored and read as an architectural form.
\end{abstract}




\section{Keywords}

architecture

Cipriani

Giotto

graphic novel

McGuire

Trabizian

Wallinger

Ware

\section{Introduction}

This article has an ambition to inform and develop the interaction between the graphic novel form and architecture, allowing us to consider the possibility of architectural structures as an alternative to the book form. There are two questions to be posed here, the initial one being: Does a synergistic relationship exist between the graphic novel and architecture that would lend itself to the authoring of graphic novels within an architectural context?

Consequently, the second question to be addressed is: How might such images be authored and read as a form of graphic novel within an architectural context? To address these questions a line of enquiry is pursued throughout the article that engages with the representation and experience of space and time in both architecture and the graphic novel, and more particularly the part played by decoration as a narrative device. 
An analysis of McGuire's Here (2014) and Ware's, Lost Buildings (Glass et al. 2004) respond to the question posed concerning a synergistic relationship between architecture and the graphic novel. Here and Lost Buildings provide evidence of a sophisticated understanding and use of architectural reference. The fact that these illustrators make use of architectural imagery as narrative devices in their graphic novels points to the potential for a synergy between architectural structure and narrative form. It is this synergy that allows us to consider the possibility of images functioning within architecture as a form of graphic novel.

The article then moves on to examine late medieval works by Giotto in two Italian chapels. Giotto's work provides us with further evidence of a synergistic relationship between architecture and the form of the graphic novel. Giotto's images, based on sacred narratives, adorn the interior of the chapels invoking reflective and contemplative states. In a similar manner to McGuire's Here and Ware's Lost Buildings Giotto provides evidence of a sophisticated understanding and use of architectural reference to inform narrative. The frescos also exhibit many of the properties and visual strategies that are to be found in graphic novels. An analysis of Giotto's work also responds to the second question (How might architectural structures and contexts be authored and read as a form of graphic novel?) The authoritative research of Laura Jacobus and Jenetta Rebold Benton is used to analyse the fusion between narrative, image and architectural structure in Giotto's work and to identify three visual strategies used by Giotto. Jacobus' and Rebold Benton's research on the congregation's interaction with the frescos, the architecture and the extended physical context of the sites as a whole experience is of 
particular interest to this article. Their research demonstrates that Giotto's application of imagery effectively allows the congregation to become readers of sacred narrative through their interaction with architecture.

Having established a synergistic relationship between architecture and the graphic novel and also identified three strategies for the authoring of illustrative imagery within an architectural context, Jacobus' and Rebold Benton's research is applied to three contemporary examples where architecture and imagery are combined to communicate narrative. The contemporary examples that are analysed are two projects commissioned as part of Transport for London's Art on the Underground projects and The Factory project in Hong Kong by Alberto Cipriani of RAD architects.

\section{Architectural imagery and the graphic novel: Here by Richard McGuire}

McGuire's Here 2014 relies upon the enduring images of a single room within a domestic building to establish the passage of time, a key concept of this graphic novel. The passage of time is, however, complicated. The physical temporal journey through McGuire's book is a conventional linear page turning process but the conceptual journey is not.

Figure 1: Richard McGuire, Here, 2014, printed book, courtesy of Richard McGuire.

Figure 2: Richard McGuire, Here, 2014, printed book, courtesy of Richard McGuire.

Most double page spreads are anchored in the interior space of a room or the place that room would occupy in the local geography before, or after, its existence. The corner of 
the room consistently occupies the central gutter of the book and other key features such as the lines that describe the meeting of the walls with the floor and the ceilings are also constant throughout the book, see Figures 1, 2, 4 and 5. The far corner of the room and the centre fold of the book establish a direct relationship between the physical structures of the room and the physical aspects of the book form. As pages are turned the time frames shift, the décor of the room changes and each change is indexed against a year date that appears as a small tag in the corner of the image. These changes move forward and backwards in time, revealing events from the past, present and future that play out in the same space. Pages also invariably feature inserted frames that act as windows, showing multiple time periods in exactly the same space. These frames also carry small date tags. At times the dominant image is of the room with smaller inserts revealing events from different periods in time. Some of these time frames pre-date or post-date the existence of the building. At other points in the book the page is dominated by a space that pre or post-dates the building and the room appears as smaller inserts, or may not appear at all, as seen in Figure 3.

Figure 3: Richard McGuire, Here, 2014, printed book, courtesy of Richard McGuire.

Figure 4: Richard McGuire, Here, 2014, printed book, courtesy of Richard McGuire.

The potential chaos that this complexity might generate in the mind of the reader is countered and calmed by a consistency of visual language and narrative content throughout the novel. McGuire tells a touching and sensitive story of the human 
condition based on autobiographical and carefully researched content. The generations McGuire shows us all play out their lives to a similar tune, suffering, enjoying and enduring different aspects of their journey through life. Furthermore, he not only shows us the transient nature of our individual lives but also that of humanity as a whole. Micro and macro time spans are represented in the book, from passing seconds to passing millennia, but the majority of the content focuses on the time span of events played out in the room. The passage of narrative time represented is at times accelerated, through the representation of fast-moving events such as an arrow in flight or a falling object, and at other points time is slowed. In Figure 3 an arrow is in flight which was let loose from a bow thirteen pages earlier. The following fourteenth page, shown in Figure 4, transforms the speeding arrow into a children's game of Pin the Tail on the Donkey. The hunters' deadly shot becomes visually echoed in a tentative act of play. The speed of an arrow in flight is contrasted with the slow, hesitant movements of the girl. As the actions and intentions of the archer and the child echo and contrast with each other, across the centuries that separate these two acts, time is poetically collapsed.

Figure 5: Richard McGuire, Here, 2014, printed book, courtesy of Richard McGuire.

Passages of time covering decades are represented through the referencing of decorative features through the depiction of changing fashions such as interior décor, clothing or cultural trends. Varying flow rates of time may all exist in a singular double page spread. The concept of memory and remembering as an indicator of time passed is also frequently visited. The taking of family photographs shown in Figure 1 is revisited across 
many years and pages as seen in Figure 2. The viewing of home movies, characters recalling personal histories or being asked to retell jokes all contribute to this sense of time. The third image of the book shows us a woman alone in her 1957 room asking herself 'hmm [...] now why did I come in here again?' (McGuire 2014: n.pag.). The last image of the book returns to the same room a moment later, at the point where she is picking up a book from the coffee table saying 'now I remember' (McGuire 2014: n.pag.). Here fallible memory and her act of remembering concern a book, that is in itself a self-referential repository of memory, and a measure of time past. The conceptual complexity of McGuire's book and its narrative structure is in itself ornamental. The twists and turns, the rhythms and repetitions, the sameness and the difference are like the forms of arabesques that have an inherent beauty and magnetism. Figure 5 shows us this in the form of a dance with ornamental postures that in 2014 literally form an arabesque. Conceptually the dance is echoed across 72 years to the accompaniment of a solo piano, consequently we are presented with both the sameness and the difference of generations of humanity framed by the enduring structure of a singular architectural space.

\section{Architectural imagery and the graphic novel: Lost Buildings by Ira Glass: Chris Ware and Tim Samuelson}

Chris Ware's contribution to the book and DVD, Lost Buildings, (Ware 2004), provides us with good evidence concerning the use of architectural imagery in illustrative practice. This work is the product of a collaboration between Ira Glass, Chris Ware and Tim Samuelson and while the book is difficult to locate in the United Kingdom, the DVD is widely available to view online. 
The work originated from an audio-visual theatrical presentation commissioned by the public radio show, This American Life that was illustrated by Chris Ware and narrated by architectural historian Tim Samuelson. The presentation transposes the graphic novel form into an audio-visual format and tells the story of Samuelson growing up in Chicago, his obsession with the architecture of Louis Sullivan and his friendship with Richard Nickel. Nickel was an architectural preservationist who died after being hit by falling debris, while salvaging material from a Sullivan building that was in the process of being demolished. Ware's illustrations at the beginning of the DVD show us Samuelson's childhood interest in architectural detail, especially in relation to Louis Sullivan's work. The narrative then progresses to show us Samuelson as a school child where he imagines himself transported through time by visualizing the original historic details of his classroom replacing its modernized features (Glass et. al. 2004). At an early age Samuelson appears to be intuitively aware of an architectural measure of time and the ability for the ornamental and decorative features of a building to index the passage of time. This measure of time that can be described as 'architectural time' is an important narrative device in the opening scenes of Lost Buildings. Throughout the work Ware's drawings illustrate a melancholic destruction of architectural monuments alongside a touching human narrative. Ware's images pay close attention to the ornamental and decorative detailing of Louis Sullivan's buildings, often referring to the language and form of architectural plans and drawings. This reminds us that architecture is primarily a process of drawing that precedes the construction of any building and, as in this case, is often a record of buildings that no longer exist. Ware's use of the style and substance of architectural drawings within the form of the graphic novel acts as a bridge between the 
form of the architectural structures featured and the form of the graphic novel. Within Lost Buildings and his later graphic novel, Building Stories (Ware 2012), such drawings are juxtaposed against broader urban vistas and interiors that make use of a pictorial space constructed using parallel projection. This use of parallel projection adopts the form of pictorial space more readily associated with architectural design drawings. Whilst parallel projection lacks the convincing illusion of space found in perspective drawing it is useful in making clear the dimensions of an object or structure. Ware's use of mechanistic parallel projection in his illustrations results in a lack of spatial illusion that he counters by rendering the images with naturalistic and expressive colour pallets. The use of this colour pallet establishes an intriguing tension between the expressive content and the mechanistic nature of the pictorial space. The imagery in these works also makes a play between the minimalist nature of the images and the complexity of the decorative surfaces, designed by Sullivan, which they depict. Sullivan's architecture is an important presence in Lost Buildings but can also be considered as further evidence of the synergy between the practice of illustration and architecture in its own right. In her book, Evolving Transcendentalism in Literature and Architecture: Frank Furness, Louis Sullivan, and Frank Lloyd Wright, Naomi Tana Uechi discusses Sullivan's response to Walt Whitman's poetry both in his architecture and in the poems that he created himself. Uechi focuses her attention on Chicago's Auditorium Theatre, 1889, and the Transportation Building, 1893 and sees Sullivan's architectural projects as a concrete manifestation of philosophical and poetic thought (Uechi 2013). From this position it is reasonable to think of Sullivan's use of form and highly decorative architectural features as an illustrative application of his Transcendentalist 
philosophy and interest in a developing North American cultural and political consciousness. Sullivan saw his architecture as a rhetorical form that communicated sophisticated ideas to mass audiences. Therefore, it could be argued that the buildings effectively act as illustrations to philosophical texts.

Uechi quotes Lewis Mumford describing Sullivan as 'the Whitman of American architecture' (Uiechi 2013: 45) and she then goes on to write, 'As Mumford mentions, Sullivan's architectural ornament is similar to Whitman's poems in their characteristic and stylistic combination of two opposing aspects - innovation and sensitivity, ornate beauty and simplicity, fierce nationalism and rugged individualism' (Uiechi 2013: 45).

Uechi's position on Sullivan's architecture also allows us to construct parallels between Sullivan and Ware. In a general sense, both Sullivan and Ware are delivering a critical engagement with the history and sociology of the United States in a poetic and philosophical form. Sullivan is using the decorative rhetoric of architecture to beguile the users of his buildings whereas Ware makes use of the graphic novel. However, both have authored a complex and meaningful content that invites their respective audiences to read and reflect on the human condition in its broader social context. It would be unreasonable to consider Sullivan's ornamental designs functioning as a graphic novel but they do provide evidence of decorative surfaces functioning in an illustrative manner.

Ware and McGuire have provided us with examples of the depiction of architectural forms functioning as essential narrative devices within their graphic novels. Both Ware and McGuire rely on the audience's ability to intuitively read architecture, within the 
pictorial space of the graphic novel, as spatial and temporal signifiers. When the passage of time is measured in architectural terms we consider a building's potential to endure the passing of many generations and hold the traces and memories of past lives. Both Ware and McGuire make use of this 'architectural time' and use it to poetic effect. McGuire and Ware understand that buildings speak of their past through the signs of style, modification, adaptation and ruin. We can understand the depiction of architecture in Ware's Lost Buildings and McGuire's Here as a kind of time machine. Both Ware and McGuire make use of images from different time periods inserted as frames within larger images allowing the audience to effectively visualize the same place at differing points in time. Both Ware and McGuire make extensive use of architectural forms in these works to not only establish a stage where the narrative is played out but also to act as an essential driver for the narrative itself. McGuire and Ware make effective use of a narrative synergy that exists between architecture and the form of the graphic novel. Louis Sullivan's architecture also provides us with good evidence of how illustrative practice has the potential to function within the context of architecture via decorative forms. In the next section, late medieval works attributed to the architect and painter Giotto provide more evidence concerning the synergistic relationship between the graphic novel form and architectural form. Giotto's work is also used to address the second question posed in the introduction that asks: How might images be authored and read as a form of graphic novel within an architectural context? Authoritative research by Jacobus and Rebold Benton on Giotto's work addresses the second question through the identification of the visual strategies employed by Giotto and the audience's reception of the work. 


\section{Giotto's work in The Scrovegni Chapel, Padua and San Francesco, Assisi, Giotto}

Two historic examples of a synergy between illustration and architecture can be found in work attributed to Giotto in the Scrovegni Chapel, Padua and the Upper church of San Francesco, Assisi, see Figures 6-9. Giotto (approx 1267-1337) was both an architect and a painter who used a range of visual strategies to enhance the audience's reading and experience of the narratives presented in the frescos at Padua and Assisi.

Giotto's frescos have been thoroughly analysed through the lens of art history and some of the valuable and insightful findings resulting from the research of Jacobus and Rebold Benton are used in this text. Giotto's work at Padua and Assisi are relevant to the questions that this article poses because of their consistent inclusion and treatment of architectural references, their representation of time, and the use of decoration to inform narrative; characteristics that are shared with the previously discussed works of McGuire and Ware.

Jacobus' and Rebold Benton's research points to Giotto's use of visual strategies to break down the barrier between the experienced space/time of the audience's real world and that of the world that is to be found in the pictorial space/time of the paintings. Steve Braund discusses the potential for illustrators to generate narrative in what he describes as the readers story world space through the Brechtian concept of the fourth wall (2015: 267-85). Braund's proposal focuses on illustrative books but could also be used to understand some of the visual strategies used in Giotto's works at both Padua and Assisi. To consider the work of Giotto from the position of illustrative practice is unusual but entirely reasonable once some basic characteristics of graphic novels are compared with 
Giotto's frescos at Padua and Assisi. For example; the sequential use of scenes, the use of visual strategies to pause, slow or quicken action from one scene to another, compositional elements to lead the readers eye from one scene to another or the use of multiple threads of narrative within a single image, organized through compositional devices such as size, scale or positioning in pictorial space. As with graphic novels Giotto's images have a close relationship with a text and in their most basic reading progress scene by scene around the interior of the chapel in what are described as 'registers'. This linear journey begins, in the case of Padua, in the top left corner of the south wall progressing around the room and then dropping to a lower register, finally completing its journey, after three circuits of the space, in the lower right-hand corner of the North wall. The similarity to the sequential form of scenes employed in graphic novels is clear. The order and design of Giotto's imagery closely refers to its architectural context, in much the same way that a graphic novel refers to its context of the book form. The book's essential structure of a progression of page turning acts is conditioned by features such as; size, format, gate folds, double page spreads, concertina books, paper engineering and cut outs, etc. All of which respond to, and inform, our interaction with the narrative. Analogous physical features are to be found in the work of Giotto at Padua and Assisi. The size, scale and shape of the architectural space, the presence of doors, windows or columns that interrupt the wall surface, or the presence of corners, curves, arches and recesses inform the form and the function of the frescos.

It is possible to apply some of the visual strategies identified in Giotto's work by Jacobus and Rebold Benton to an analysis of contemporary examples of architecture where imagery has been used as a site-specific feature within a building. 
Three of the strategies employed by Giotto as described by Jacobus and Rebold Benton are;

1. The use of convincing illusionistic painting to describe spaces receding into the walls or decorative architectural features that project out from walls

2. The use of threshold imagery to prepare the congregation for the transition between secular and sacred spaces as they enter, or exit, the chapel

3. The inclusion of experienced events, local architecture or the interior features of the chapel within the sacred story world of the frescos.

The first of the three strategies is evident at both Padua and Assisi and makes use of convincing illusionistic imagery to project decorative architectural features out from, and into, the picture plane. The illusionistic imagery takes the form of decorative banding. This banding frames the imagery, defining a boundary between different scenes. The banding also acts as a frame through which we look into pictorial space. On the West wall of the chapel there is a judgement day painting, shown in Figure 7. The chapel's patron Enrico Scrovegni is pictured here with a cleric who is offering the chapel to God. This is a critical act in the relationship between the Scovegni family and the church of that period. The wealth of the Scrovegni family was built upon the sin of money lending, a fact that limited the family's ambitions. However during this period the church came to 
realize a new reliance on mercantile wealth within an emerging urban context (Little 1983). Consequently, the Scrovegni family sought to rehabilitate the family name through the funding of a magnificent chapel. The link between the family's real-world sociopolitical narrative and the church's sacred narrative is signalled through the inclusion of the offering of the chapel within the Judgement Day fresco. The insert in Figure 7 shows the cleric's gown falling out of pictorial space over the decorative banding into the viewers space, breaking through what Steve Braund describes in Brechtian terms as a fourth wall (Braund 2015: 267-85). The boundary between pictorial space and real space is punctured as the cleric is in both pictorial space and the real world of the audience. A crucial element in puncturing this boundary is the decorative banding that runs around the image. To further confuse our understanding of the boundary between pictorial space and real space, the decorative banding is an illusion of threedimensional decorative mouldings and columns that project into the real-world spacetime of the viewer, see Figure 7. The complex relationship between the pictorial space of the judgment day painting, the cleric's foot and the decorative banding subverts and disrupts the viewer's understanding of the picture plane allowing sacred narratives from within the pictorial space of the painting to be blended with the actual space of the audience. This has the effect of achieving what Braund describes as the creation of story worlds in the reader's space (2015).

Giotto also uses decorative banding in his frescos in the upper church of San Francesco in Assisi. Janetta Rebold Benton's research has made a convincing case to explain how the decorative banding at Assisi is designed to subtly control the points at which an audience would pause to read sections of a very long register of frescos (1989). 
The frescoes are to be read in groups of three as shown in Figure 9. Each group of frescos is framed by a painted decorative band of illusionistic corbels supporting an equally illusionistic pediment. Rebold Benton's research asserts that the illusionistic painting techniques encourage us to perceive the bands as real world ornamental architectural details. The single vanishing point for the corbels works best when we position ourselves at the centre of each group of images. This strategy is repeated along the full length of the walls. The illusionistic decorative banding effectively punctuates the audience's progress, subtly controlling pace and flow through the narrative.

A third example of illusionistic imagery, that disrupts the barrier between real and pictorial space, takes the form of illusionary rooms in the lower register either side of the triumphal arch in the Padua chapel, as shown in Figure 6. These frescos trick the eye into believing that actual rooms exist on either side of the arch. Jacobus' research into the work of Giotto asserts that the painted surfaces of walls operate as a liminal space between our real space time and the fictive pictorial space time of the painting, and the disruption of this surface is used to explore the tension between real life experience and sacred narrative (Jacobus 1999: 102). The trick of these illusionistic rooms, like that of the illusionistic columns and mouldings, is to disrupt the barrier between real and pictorial space, achieving what Braund describes as a story world in the reader's space (2015).

The second of the three strategies is also designed to blend real and pictorial spaces to create a story world in the reader's space and involves the repeating image of a pulpit in the Padua Chapel. The pulpit appears in multiple paintings around the chapel, always 
pictured at a different angle. Figure 8 shows us one example of this. Jacobus points out that this reoccurring image of the pulpit appears in frescos at strategic points around the chapel walls. She goes on to propose that this pulpit is an image that would have borne a striking similarity to the real pulpit within the chapel, and the viewing angles of the pulpits in the various paintings echo the viewing angles of the actual pulpit from the positions where the paintings would have been viewed. For example, when the congregation enter and turn into the space of the chapel they would see the painting in Figure 8. The fictive structure in the painting is then echoed with the actual viewing angle of the pulpit structure at the end of the chapel. Jacobus defines these scenes as 'threshold' images whose function is to aid the congregation's transition from secular to sacred space. This is achieved by referencing actual structures of the internal architecture into the pictorial space and narrative time of the frescos (Jacobus 2008).

The final strategy makes use of the audience's journey through the real and experienced space and time of the building, and the local environment, to reinforce and deepen the audience's connection with the narrative journeys described in the pictorial space and narrative time.

Figure 6: Giotto, Triumphal Arch, c. 1306, Fresco, Scrovegni chapel, Padua, Italy, courtesy of Web Gallery of Art.

In Padua the upper part of the chapel wall, above the triumphal arch, is the site of the annunciation paintings, see Figure 6. Jacobus understands these annunciation scenes as 
depicting an annual enactment of the annunciation as opposed to the annunciation itself. Her argument is based, in part, on the clothing worn by the figures as she locates the style of the garments as being late thirteenth century, as opposed to the garments depicted elsewhere in the chapel that place characters within a biblical period (Jacobus 1999). Consequently the congregation's viewing experience is that of actors playing the narrative as opposed to images that visualize the actual annunciation. The congregation's memory of real theatrical events is represented in pictorial space, enhancing their reading of the architecture, its site and the imagery.

Figure 7: Giotto, Judgement Day painting, date unknown, Fresco, Scrovegni Chapel, Padua, Italy, photo courtesy of Elena di Monti.

Figure 8: Giotto, The Presentation of Mary in the Temple, c. 1306, Scrovegni Chapel, Padua, Italy, photo courtesy of Elena di Monti.

Figure 9: Giotto, The Homage from the Simple Man, St Francis giving his Cloak to the Poor Knight and The Vision of the Palace of Arms, Upper Church, Assisi, Italy, courtesy of Web Gallery of Art.

Similar to the referencing of annunciation enactments within the annunciation painting, a fresco in Assisi Giotto makes reference to a local and still existing Roman temple. This can be seen in the left-hand section of the fresco in Figure 9. The inclusion of this temple within the image helps the audience to relate sacred narrative to their real-world 
experience.

The three strategies identified above demonstrate how the use of decorative imagery is integral to the intended rhetoric of the chapels. In contrast, the following contemporary examples are secular. Parallels can however be drawn between the historic and the contemporary works discussed in this article, through the application of research by Jacobus, Rebold Benton and Braund.

Figure 10: Maurio Marchesi for RAD (Aaron Tan, Alberto Cipriani), The Factory, Aberdeen, Hong Kong, 2008, courtesy of RAD Architects, photographs Steve Wikeley.

\section{The Factory, Hong Kong, 2008, A. Cipriani for RAD architects}

The Factory, Hong Kong, was an industrial building refurbished and repurposed as studios for the creative industries in 2008 by RAD architects. Large wall paintings, as seen in Figure 10, were commissioned from the illustrator Mauro Marchesi as part of the

development. The decorative paintings occur throughout the building taking advantage of the building's structure to inform and enrich the fictional narrative. The Hollywood Bau story begins in the wider city before moving into the lower level of the building after a car chase and concluding on the roof following a pursuit through the levels of the building. The top left image in Figure 10 shows us the underground car park of the Factory where Hollywood Bau catches up with a diamond thief, the diamond falls to the floor and shatters. Each facet of the shattered diamond reveals a different narrative each 
existing in various parallel universes. The separate narratives are consequently developed through different levels of the building before concluding on the roof. Prior to refurbishment passage through the corridors would have been mundane, now the building is transformed into an engaging book form, where the user becomes a reader of real and fictive space. Marchesi's narrative encourages an exploration and re-imagining of the space and its city context by blurring the boundaries between fictive and real locations. In a Pecha Kucha presentation Alberto Cipriani of RAD describes the refurbishment project as mixing languages of architecture and illustration to create a giant multiple-choice book that allows the users of the building to become readers of the various narratives as they move through the building (Pechakucha nd). Cipriani's description of the building as a giant book acknowledges the potential of any building to be read when the languages of illustration and architecture merge. Cipriani and Marchesi have, like Giotto, incorporated the fabric of the building and its urban context into the narrative thus extending the story world into the readers' space. Threshold images, as described by Jacobus (2008) are evident on the exterior ground floor and the car park. They function to welcome the user into the building and also the narrative, matching the users own journey through the city with that of the fictive characters. They also signal a transition from normal life into the fictive world of Hollwood Bau.

\section{Art on the Underground}

Transport for London's Art on the Underground project has commissioned artists to install works across the transport network of London. In a similar way to RAD's project at The Factory, Transport for London mix the language of architectural form with the 
language of two-dimensional imagery. The following examples from London's Art on the Underground promote a reflective state of mind in passengers as they make their way through the transport system. The images invite passengers to read and question the space they pass through, acting as illustrations to the physical, emotional and conceptual journeys experienced by passengers.

\section{Art on the Underground, Mark Wallinger, Labyrinth, 2013}

Mark Wallinger's Labyrinth, 2013, has been permanently installed in all 270 underground stations and each Labyrinth differs in its design. All the images are enamel on sheet metal, a process that echoes the traditional manufacture of signage on the underground. In each station Wallinger's Labyrinth shares the ticket hall space with a visually similar, and now iconic, schematic graphic map of the transport system.

Figure 11: Mark Wallinger for Art on the Underground, Labyrinth, Embankment Tube Station, London, 2013, courtesy of Art on the Underground, photo Theirry Bal.

Both the London Tube map and the labyrinth conceptualize space and time, acting as an illustration of the passengers' journey. The map however is an illustration of the problematic choices between points of departure and destination presented as a maze. On

the other hand, Wallinger's Labyrinth introduces a poetic transport, the single pathway of a labyrinth avoids problems of choice, it focuses and calms the viewer if they choose to carefully trace a path to its inevitable outcome. The transport map is also an index of 
time, in that it is used to gauge the quickest and shortest journey through an unknowable space. In contrast to this the labyrinth attempts to create a timeless, contemplative state. In this work Wallinger is making reference to the historical use of labyrinths. Chartres cathedral has a large labyrinth embedded into the floor. Pilgrims would, on arrival, walk the labyrinth and the journey would calm and focus them in preparation for the conclusion of their sacred journey. The labyrinth acts as a threshold image, illustrating the passage from secular to sacred space, as described in the earlier discussion of Giotto's work at Padua. Positioned in every station, Wallinger's Labyrinth may also be read as a threshold image preparing the passenger for the transition to and from subterranean space. The transport map and the labyrinth are both conceptualizations of space and time designed to aid the transition from knowable space above ground to a disorienting and unknowable space below. The appearance at every station of the Labyrinth and its visual similarity to the underground map also illustrates the sameness and the difference that we encounter as we are transported through the whole network and the disorienting effect this has upon us.

\section{Art on the Underground, you don't know what nights are like, Mitra Tabrizian,}

\section{January 2017 to November 2018}

Situated at Southwark Tube Station, Mitra Tabrizian's temporary Transport for London art project you don't know what nights are like took the form of large photographs that decorated the exterior faces of the station. The image shown in Figure 12, illustrates the largely hidden lives of London's night workers and the part played by Transport for London in their transportation from the edge of the city into their central London 
workplaces. Tabrizian's project, like Wallinger's Labyrinth, illustrates a conceptual reading of the whole network. Both Tabrizian and Wallinger also make use of threshold imagery but the threshold images work in very different ways. The threshold image of a Labyrinth sited at each station illustrates the transition encountered when entering or exiting the transport system. In contrast, Tabrizian infers the potential for the whole transport system to become a threshold space between different social and economic areas of the city. Tabrizian invites her audience to read the transport network as a site where the personal narratives of night workers are inscribed. Short passages of text from interviews with night workers accompany the images that surround Southwark Tube Station, allowing the audience to construct narratives from the real-life experiences of others. Eleanor Pinfold, Head of Art on the Underground, describes these texts as internal voices that reflect on lost time (Art on the Underground n.d.).

The work invites the audience to blend their own real and immediate experience with that illustrated by the photographs. Tabrizian uses subtle visual signifiers in her images, such as a bus stop and a railway viaduct, to link the immediate experience of the geographic near, with the imagined far, and the sense of twilight in the photographs operates as a liminal space, signifying the transition from one state into another. In Figure 12 we see an interesting juxtaposition of a block of flats that might be inhabited by a night worker with the type of building in which they might work. The image also makes opportunistic use of a bike rack that could, due to the size and scale of the image, conceivably exist within the picture. Consequently, the real and the pictorial spaces become confused and refer to each other. The tube station is therefore identified not solely as part of a system that 
mechanistically transports us through geographic spaces, characterized by social and economic boundaries, but one which also transports us poetically into a conceptual space where a reflective inner voice may construct narratives.

Tabrizian's work directs us to the poetic in the everyday. She also anchors the images within a very real sociopolitical context. Similarly, the Scrovegni chapel combines a beguiling poetic narrative with the sociopolitical terrain of the period. Both works seek to bring, through a process of 'reading', a sense of the poetic to their respective audiences and to transport them through the blending of real and fictive experience to an internally reflective space.

Art on the Underground projects are intended to enrich the transport environment and change the way passengers experience the city. Wallinger's and Trabizian's works invite users to read not only the images but also the city spaces which they occupy, potentially seeing themselves as actors in illustrations generated from the narrative of the city.

Figure 12: Mitra Tabrizian for Art on the Underground, you don't know what nights are like, Southwark Tube Station, London, January 2017-November 2018, courtesy of Art on the Underground, photo Theirry Bal.

\section{Conclusion}

The idea of reading architectural structures as language is contested from the architectural point of view, though we can certainly think of architecture as being language like and there being an architectural rhetoric or voice (Forty 2000: 62-85). We can also consider an established phenomenology of architecture as being part of an instinctual and poetic 
'reading' of buildings (Bachelard 2014). Both McGuire and Ware have made use of architectural rhetoric and an audiences' ability to make instinctual and poetic readings of architectural references within their graphic novels. The use made of architecture as both a subject and a narrative device in McGuire's and Ware's work is evidence of a synergistic relationship between architecture and the graphic novel.

However, to develop the idea of 'reading' architecture, as we might read a graphic novel, it is necessary to develop the non-specific rhetoric of architecture into a specific narrative and make use of our instinctual and poetic responses to architectural spaces. Giotto’s frescos demonstrate how decorative imagery can be authored in architectural contexts, allowing for the building to be read as we might read a graphic novel and that it is essential for the decorative imagery to explicitly respond to the existing form, function or rhetoric of the architecture and its wider context.

The research of Jacobus and Rebold Benton has been crucial in understanding Giotto's work and also providing an analytical frame work to examine contemporary examples such as Wallinger's and Trabizian's Art on the Underground projects and RAD's refurbishment of The Factory. Braund, Jacobus and Rebold Benton have all examined how the disruption of the barrier between real and pictorial space, and, experienced time and narrative time is an effective strategy to create story worlds in the reader's space deepening their involvement with the narrative. In conclusion, there is clear potential for graphic novelists to work directly with architectural structures, authoring narratives that are read as part of architectural spaces. Such graphic novels have the potential to exist in experienced time and narrative time, real space and pictorial space. Graphic novels that are authored specifically for architectural spaces allow buildings to become repositories 
of stories that can conceptually alter and enrich our experience of the built environment.

\section{References}

Art on the Underground (nd), 'you don't know what nights are like? Mitra Trabizian', https://art.tfl.gov.uk/projects/you-dont-know-what-nights-are-

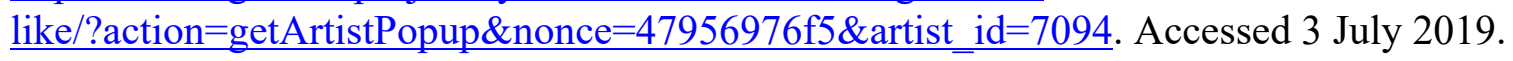

Bachelard, Gaston (2014), The Poetics of Space, New York: Penguin Group.

Braund, Steve (2015), 'The itinerant illustration: Creating storyworlds in the reader's space', Journal of Illustration, 2:2, pp. 267-85.

Pechakucha 20 images 20 seconds (nd), 'Cipriani, Alberto', https://www.pechakucha.com/presentations/the-factory-3. Accessed 3 July 2019.

Forty, Adrian (2000), Words and Buildings, A Vocabulary of Modern Architecture, London: Thames and Hudson.

Glass, Ira, Ware, Chris and Samuelson, Tim (2004), Lost Buildings, Chicago: WBEZ.

Jacobus, Laura (1999), 'Giotto's annuciation in the Arena Chapel, Padua', The Art Bulletin, 18:1, March, pp. 93-107.

(2008), Giotto and the Arena Chapel: Art, Architecture and Experience, London: Harvey Miller Publishers.

Little, Lester (1983), Religious Poverty and the Profit Economy in Medieval Europe, Ithica: Cornell University Press.

McGuire, Richard (2014), Here, London: Penguin Books.

Rebold Benton, Janeta (1989), 'Perspective and the spectator's pattern of circulation in Assisi and Paudua', Artibus et Historiae, 10:19, pp. 37-55.

Uechi, Naomi Tanabe (2013), Evolving Transcendentalism in Literature and Architecture: Frank Furness, Louis Sullivan, and Frank Lloyd Wright, Newcastle upon Tyne: Cambridge Scholars Publishing.

Ware, Chris (2004) Lost Buildings,

Ware, Chris (2012) Building Stories, New York: Pantheon Books 


\section{Contributor details}

Laurence North teaches Illustration and Architecture at Falmouth University. He produces studio based visual work alongside conference papers and articles. Interests include the relationship between Architecture and Illustration.

\section{Contact;}

Laurence North

Falmouth School of Art

Falmouth University

Woodlane

Falmouth

Cornwall

TR11 4RA

Laurence@,falmouth.ac.uk

Orcid ID

https://orcid.org/0000-0002-6578-1771 